\title{
AÇÃO DE EDUCAÇÃO POPULAR EM SAÚDE SOBRE O ALEITAMENTO MATERNO
}

\author{
POPULAR HEALTH EDUCATION ACTION ON BREASTFEEDING
}

\author{
Jerssica Mayara Agustinho da Silva ${ }^{1}$
}

\begin{abstract}
RESUMO: Objetivo: Trocas de experiências e saberes populares sobre o aleitamento materno, alimentação e saúde bucal e adquirir conhecimento em uma roda de conversa sobre o aleitamento materno, alimentação e saúde bucal. Método: Trata-se de um relato de experiência realizado por residentes do Programa de Residência em Saúde da Família e Comunidade (Secretaria Municipal de Saúde João Pessoa/Faculdade de Ciências Médicas) no ano de 2019, realizado na cidade de João Pessoa/Paraíba. O público gestante do $1^{\circ}, 2^{\circ}$ e $3^{\circ}$ trimestre para compartilhar experiências e trocar informações e curiosidades sobre o aleitamento materno, alimentação na gestação e saúde bucal. Resultados: $O$ tema da atividade foi trocas de experiências e saberes populares sobre o aleitamento materno que abordavam a pega correta da mama na hora de amamentar o recém-nascido, posicionamento correto, higiene oral do bebê, saúde bucal da no período gestacional, tipos de partos e orientações de alimentação durante a gestação e o aleitamento materno. A atividade foi iniciada com uma dinâmica de autoconhecimento, em que as participantes abriam uma caixa e falava da pessoa que via no espelho sem se identificar. Em seguida foi iniciado as falas emque a roda de conversa foi conduzida de acordo com as experiências das gestantes e sendo compartilhada com todos os participantes. Conclusão: Levando em consideração os aspectos mencionados a educação popular se fez presente com a troca de experiências das pacientes como os profissionais, sendo relevante o processo da escuta e acolhida nos ambientes de trabalho para assim fortalecer cada vez a educação popular.
\end{abstract}

Palavras chave: Aleitamento Materno. Saúde da Família. Equipe de Assistência ao Paciente

\footnotetext{
${ }^{1}$ Fisioterapeuta, graduada pela Universidade Federal da Paraíba (UFPB); Residente no Programa de Residência Multiprofissional em Saúde da Família e Comunidade (Secretaria Municipal de Saúde João Pessoa/Faculdade de Ciências Médicas).
} 
ABSTRACT: Objective: Exchange of experiences and popular knowledge about breastfeeding, food and oral health and acquire knowledge in a conversation wheel about breastfeeding, food and oral health. Method: This is an experience report conducted by residents of the Family and Community Health Residency Program (João Pessoa Municipal Health Secretariat / Medical Sciences College) in 2019, held in the city of João Pessoa / Paraíba. The pregnant public ofthe 1st, 2nd and 3rd trimester to share experiences and exchange information and curiosities about breastfeeding, food and oral health. Results: The theme of the activity was exchanges of experiences and popular knowledge about breastfeeding that addressed the correct attachment of the breast when breastfeeding the newborn, correct positioning, oral hygiene of the baby, oral health during pregnancy, types of breastfeeding. childbirth and feeding guidelines during pregnancy and breastfeeding. The activity started with a self- knowledge dynamic, in which participants opened a box and talked about the person they saw in the mirror without identifying themselves. Then began the speeches in which the conversation wheel was conducted according to the experiences of pregnant women and being shared with all participants. Conclusion: Taking into consideration the mentioned aspects, popular education was present with the exchange of experiences of patients asprofessionals, being relevant the process of listening and welcoming in the workenvironments to strengthen each time the popular education.

Keywords: Breast Feeding. Family Health. Patient Care Team. 


\section{INTRODUÇÃO}

Estudos apontam que apenas $41 \%$ das crianças no Brasil são amamentadas até aos 6 meses de vida (ÓRIA et al., 2018; VENANCIO et al., 2010). Porém vários fatores podem influenciar esses dados, como por exemplo a situação sócio econômica que gera falta de alimentação adequada para mãe e o bebê. Outrossim é pouco leite produzido pela mãe após o parto, ou seja, não sendo o suficiente para atender a demanda do filho, outros comportamentos podem levar a diminuição da quantidade do leite como a ansiedade, insegurança estão no contexto das interrupções da amamentação (MINISTÉRIO DA SAÚDE, 2010).

LIMA et al., 2019, afirmar que o relato de pouco leite é um problema complexo, que transpõe linhas culturais, geográficas e socioeconômicas. Mas essa demanda pode ser diminuída a partir de orientações e práticas educativas de como ofertar o leite materno que na maioria das vezes o incentivo a mamada leva sim a grande produção do leite, sendo assim satisfaz a fome da criança e proporciona ganha de peso.

Recomenda-se amamentação exclusiva até o sexto mês de vida sendo complementado até 2 anos de idade ou mais, segundo a Organização Mundial da Saúde (OMS). O leite materno possui nutrientes para proteção de doenças para o bebê, com ele adquire-se anticorpos capaz de combater as diarreias, pneumonias, diabetes e entre outras doenças(ZOCATELLI et al., 2019).

Existem muitas evidencias cientificas que trazem os benefícios do aleitamento materno para a criança, desencadeando a promoção e prevenção de agravos a saúde mãe- bebê, cabe aos profissionais e familiares apoiarem essa faze da mulher com informações essências para aprimorar e abranger essa demanda (DINIZ et al., 2019).

As orientações são de fundamental importância, pois influenciam diretamente na forma correta de amamentar deixando a mulher mais capacitada e empoderada para ofertar o leite ao seu filho, pois observamos claramente o fator cultural que está 
presente nos territórios de classe baixa, mas não desmerece aquela população para se ter um pratica adequada (LIMA et al., 2019).

Entretanto com várias práticas educativas e um setor grande de comunicação, ainda observamos taxas baixas além do recomendado para a amamentação. Promover saúde é de fundamental importância para adquirir melhorias nos índices de aleitamento, para que possamos garantir cada vez mais decrescente as taxas de mortalidade na infância (ROCCl et al., 2014).

Uma forma de promoção da saúde é a educação popular em saúde, publicada em 19de novembro de 2013 à Política Nacional de Educação Popular em Saúde (PNEP-SUS), onde se propõe metodologias e tecnologias para o fortalecimento do Sistema Único de Saúde (SUS). É uma prática voltada para a promoção, proteção e a recuperação da saúde a partir do diálogo entre a diversidade de saberes, valorizando os saberes populares, a ancestralidade, a produção de conhecimentos e a inserção destes no SUS.

As práticas e as metodologias da Educação Popular em Saúde (EPS) possibilitam o encontro entre trabalhadores e usuários, entre as equipes de saúde e os espaços das práticas populares de cuidado, entre o cotidiano dos conselhos e dos movimentos populares, resinificando saberes e práticas. A Educação Popular em Saúde propõe ações em quatro eixos estratégicos: Participação, controle social e gestão participativa; Formação, comunicação e produção de conhecimento; Cuidado em saúde; Intersetorialidade e diálogos multiculturais (BRASIL, 2013).

A educação Popular vem retratada por valorização cultural de cada região com suas especificidades, que através de autores marcantes de literaturas com por exemplo Paulo Freire deixa bem claro a importância desta prática, seu local de abordagem é a principal forma de aprendizagem e transpassarem do conhecimento popular (BRANDÃO, 2006).

No mês de agosto o Ministério da Saúde enfatiza o agosto dourado em alusão ao aleitamento materno, com isso as Estratégias de saúde da família (ESF) trabalham durante este mês as atividades voltadas à temática. Pondo em prática as metodologias de educação popular onde as trocas de conhecimento e empoderamento das mulheres de cada território, levando em consideração as especificidades de cada uma (BRASIL, 2019). 
Inserida na Atenção Primária de João Pessoa, à Unidade básica de saúde Indústrias integradas, localizada no distrito sanitário I, com a relevância da temática se adentrou a campanha a promoveu uma ação de educação popular com as gestantes do território.

\section{OBJETIVOS}

- Troca de experiência e saberes populares sobre o aleitamento materno, alimentação nagestação e saúde bucal;

- $\quad$ Adquirir conhecimento em uma roda de conversa sobre o aleitamento materno,alimentação e saúde bucal;

- $\quad$ Fortalecer o conhecimento popular com embasamento cientifico.

\section{MÉTODO}

Trata-se de um estudo descritivo, tipo relato de experiência, realizado por residentes do Programa de Residência em Saúde da Família e Comunidade (Secretaria Municipal de Saúde João Pessoa/Faculdade de Ciências Médicas) no ano de 2019, concretizado na cidade de João Pessoa/Paraíba.

Esta experiência tem uma finalidade especifica de implementar a educação popular junto a comunidade, de forma a construir os pensamentos, projetos, crenças e compreensão sobre o tema abordado, utilizando a sua principal arma que é o saber da comunidade para absorver e desenvolver um projeto político e pedagógico (GERHARD; FRANTZ, 2019).

O público alvo gestantes do $1^{\circ}, 2^{\circ}$ e $3^{\circ}$ trimestre para compartilhar experiências e trocar de informações e curiosidades sobre o aleitamento materno, alimentação na gestação e saúde bucal. 
Vale ressaltar que o presente estudo não precisou de termo de consentimento livre esclarecido por se tratar de uma pesquisa de relato de experiência.

\section{RESULTADOS E DISCUSSÃO}

A atividade foi realizada na sala de espera com as gestantes, profissionais de fisioterapia, nutricionista, enfermeiros, médico e dentista, ou seja, equipe multiprofissional. A mesma foi iniciada com uma dinâmica de autoconhecimento, onde as participantes abriam uma caixa e falava da pessoa que estava no espelho sem se identificar. Em seguida foi iniciado as falas em roda de conversa, sendo conduzida de acordo comas experiências das gestantes e compartilhada com todos os participantes. O tema da atividadefoi trocas de experiências e saberes populares sobre o aleitamento materno.

As falas foram surgindo e as dúvidas também, incialmente foi lançado a pergunta de como amamentar o recém-nascido com a pega correta da mama? As mães de segunda viajem iniciaram a fala de o bebê pegar a auréola do peito completa, não fazer um símbolo de tesoura para levar o peito até o bebê e sim pegar bem a mama e aproximar o bebê do corpo, deixarque ele se satisfaça e ter paciência e sempre ofertar as duas mamas para a criança.

O posicionamento correto de como segurar o bebê também foi abordado, para que as mamães não tivessem dores após a amamentação, uma postura confortável para mãe e recém-nascido com apoio do travesseiro sentada ou deitada, não inclinar o corpo sempre com postura ereta e confortável, neste momento contamos com a partilha da fisioterapeuta para o posicionamento correto e confortável.

A higiene oral do bebê e saúde bucal da gestante também foram mencionados a importância de uma higiene correta tanto da mãe durante a gestação, como a boca do recém-nascido nos primeiros meses de vida, a troca de saberes em limpar sempre após cada mamada do bebê e de qual maneiro fazer higienização, sempre enfatizando a importância da saúde bucal. 
O destaque da ação foi as dúvidas e trocas de experiências relacionados a alimentação, onde foi divido em 3 partes: alimentação da mãe causa cólicas no bebê? Quando se deve introduzir alimentos industrializados? E qual o que realmente ajuda na produção do leite materno?

Como de rotina para os profissionais nutricionistas a dúvida sobre alimentação da mãe e as cólicas que aparecem nas crianças nos primeiros meses de vida, sempre aparecem nesses tipos de ação ou em atendimentos ambulatoriais para esses públicos. Foi esclarecido que segundo Vitollo (2008), o aumento da incidência de cólicas em bebes em aleitamento foi relatado nos dias que as mães ingeriram chocolates e frutas. Porém, está associação ainda não é descrita em grandes estudos, não sendo completamente conhecida. Portanto, foi orientado que as mães que estão ou não em amamentação exclusiva seguir o guia alimentar e tentar consumir o menos possível gorduras, não ingerir bebidas alcoólicas e tomar no mínimo 3 litros de água por dia.

De acordo com Teixeira (2019) a implementação da Educação Popular se torna um desafio, pois vem de saberes populares, o ensinamento primordial para as outras pessoas, cadagesto e especulações são detalhes que aprimoram a troca de conhecimento e experiências já vivenciadas, deixa então bem relevante esse processo de inserção na atenção básica para os profissionais e pacientes do sistema.

Outrossim, as orientações de alimentação durante a gestação, no período puerperal e para os primeiros meses do bebê, foram debatidas com intuito de aprender e trocar informações, a diminuição do uso do açúcar e massas e utilização de frutas foram citadas para as gestantes, mas para o bebê foi bem relevante as falas da amamentação exclusiva até os 6 meses sem adicionar qualquer outro alimento inclusive água, e para o aumento na produção de leite foi orientado o consumo excessivo de líquido, desmistificando o consumo de açúcar em excesso com a produção do leito materno. No pós-parto saíram relatos e foram complementadas pelo nutricionista a importância de ingestão de alimentos que são comprovados anti-inflamatórios, para auxiliar no processo pós-cirúrgico.

Para Freire (2019), o marco da educação popular está se debruçando, ainda presenciamos um forte contexto social e político que chegam silencias suas histórias 
e trajetórias, mas que isto nos remota em cada relato uma abordagem inovadora, relevante e atuante através da experiência do outro, no contexto desmistificado a educação popular está semoldando nos ambientes do Sistema Único de Saúde.

Após o termino da roda de conversa fizemos um coffee break para todos em momento de confraternização e fortalecimento de vinculo para as usuárias. Os materiais utilizados foram bolas, toalhas, garrafas, caixas, durex, boneca de pano, peito de crochê, bandejas, copos, guardanapos, bolos e bolachas, frutas, cartilhas, notebook, papel e canetas.

\section{CONCLUSÃO}

A educação popular se faz importante, levando em consideração os aspectos mencionados pois se fez presente com a troca marcante de experiências das usuárias junto com os multiprofissionais em saúde da família. O processo da escuta e acolhida nos ambientesde trabalho fortalecer cada vez a educação popular.

Ainda salientamos que a educação Popular se mostrou mais uma vez essencial nos ambientes de atenção primária em saúde, os usuários junto com os profissionais de saúde estão presente neste contexto que visa o social e o político no sistema de saúde.

Tudo isso soma forças para ações de educação popular com o compromisso de todos (profissionais e pacientes) para o desenvolvimento da educação desmistificando o contexto (médico assistencialista).

Assim, é tamanha sua importância e real necessidade e esperamos que em um futuro breve esse formato de adquirir conhecimento possa abrir espaços para todos os meios de assistência em saúde e que assumam o seu real papel de considerar o outro capaz também de disseminar o conhecimento. 


\section{REFERÊNCIAS BIBLIOGRÁFICAS}

BRASIL, O. P. A. S. Semana Mundial de Aleitamento Materno:"Sucesso da amamentação não é responsabilidade exclusiva da mãe, mas de todos nós", afirma representante da OPAS/OMS no Brasil. 2019.

BRASIL. Ministério da Saúde. Secretária de Gestão Estratégia e Participativa. Política Nacional de Educação Permanente em Saúde (PNEPS-SUS). Comitê Nacional de Educação Permanenteem Saúde. CNEPS-SUS. Brasília-DF. Ministério da Saúde 2013.

BRANDÃO, Carlos Rodrigues. O que é educação Popular? São Paulo: Brasiliese, 2006.

CASTRO, Mariana Monteiro de; OLIVEIRA, Simone Santos. Avaliação do trabalho na Atenção Primária à Saúde do município do Rio de Janeiro: uma abordagem em saúde do trabalhador. Saúde em Debate, v. 41, p. 152-164, 2017.

DINIZ, Cinthia Martins Menino et al. Contribuições dos aplicativos móveis para a prática do aleitamento materno: revisão integrativa. Acta Paulista de Enfermagem, v. 32, n. 5, p. 571$577,2019$.

FREIRE, Ana Clara et al. Educação popular no contexto brasileiro: percepções dos representantes de movimentos sociais sobre o Marco de Referência da Educação Popular para as Políticas Públicas. 2019.

GLANZNER, Cecília Helena et al. Avaliação de indicadores e vivências de prazer/sofrimento em equipes de saúde da família com o referencial da Psicodinâmica do Trabalho. Revista Gaúcha deEnfermagem, v. 38, n. 4, 2017.

GERHARDT, M. C.; FRANTZ, W. Educação popular e movimentos sociais. Revista de Educação Popular, v. 18, n. 1, p. 92-104, 13 jun. 2019.

KATSURAYAMA, Marilise; PARENTE, Rosana Cristina Pereira; MORETTI-PIRES, Rodrigo Otávio. O trabalhador no programa saúde da família no interior do estado do Amazonas: um estudo qualitativo. Trabalho, Educação e Saúde, v. 14, n. 1, p. 183-198, 2016.

LIMA, Ana Paula Esmeraldo et al. Aleitamento materno exclusivo de prematuros e motivos para sua interrupção no primeiro mês pós-alta hospitalar. Revista Gaúcha de Enfermagem, v. 40, 2019.

Ministério da Saúde (BR). Secretaria de Atenção à Saúde. Departamento de Atenção Básica. Saúde da criança: aleitamento materno e alimentação complementar. 2. ed. Brasília (DF): Ministério da Saúde; 2015 [citado 2019 nov 19]. Disponível em: http://bvsms.saude.gov.br/bvs/publicacoes/saude_crianca_aleitamento_materno_cab23.pdf

SAMUDIO, Jania Lurdes Pires et al. Cartografia do cuidado em saúde mental no encontro entre agente comunitário de saúde e usuário. Physis: Revista de Saúde Coletiva, v. 27, p. 277-295, 2017.

SIMÕES, Arlete Lima; FREITAS, Carlos Machado de. Análise sobre condições de trabalho de Equipe de Saúde da Família, num contexto de vulnerabilidades, Manaus (AM). Saúde em Debate, v. 40, p. 47-58, 2016.

SPERONI, Katiane Sefrin et al. Percepções dos agentes comunitários de saúde: contribuições para a gestão em saúde. Revista Cuidarte, v. 7, n. 2, p. 1325-1337, 2016. 
ORIÁ, Mônica Oliveira Batista et al. Eficácia de intervenções educativas realizadas por telefone para promoção do aleitamento materno: revisão sistemática da literatura. Revista da Escola de Enfermagem da USP, v. 52, 2018.

TEIXEIRA, Maricélia da Silva. A prática educativa dos (as) agentes comunitários (as) de saúde da unidade Saúde da Família do Bairro Pasto Novo no município de Mari-PB: uma educação popular? 2019.

VENANCIO, Sonia I. et al. Breastfeeding practice in the Brazilian capital cities and the Federal District: current status and advances. Jornal de pediatria, v. 86, n. 4, p. 317-324, 2010.

VITOLLO, Márcia Regina. Nutrição: da Gestação ao Envelhecimento. Rio de Janeiro: Ed Rubio, 2008.

ZOCATELLI, Julia Beatriz et al. Tipo e Tempo de Aleitamento e Influência no Sistema Estomatognático/Type and Time of Lactation and Influence in the Stomatognathic System. Saúdeem Foco, p. 51-67, 2019. 